\title{
A comparison of clinicopathological features and prognosis in prostate cancer between atomic bomb survivors and control patients
}

\author{
KOICHI SHOJI $^{1}$, JUN TEISHIMA ${ }^{1}$, TETSUTARO HAYASHI ${ }^{1}$, SHUNSUKE SHINMEI ${ }^{1}$, \\ TOMOYUKI AKITA $^{2}$, KAZUHIRO SENTANI ${ }^{3}$, YUKIO TAKESHIMA ${ }^{4}$, KOJI ARIHIRO ${ }^{5}$, \\ JUNKO TANAKA $^{2}$, WATARU YASUI ${ }^{3}$ and AKIO MATSUBARA ${ }^{1}$ \\ Departments of ${ }^{1}$ Urology, ${ }^{2}$ Epidemiology, Infectious Disease Control and Prevention, \\ ${ }^{3}$ Molecular Pathology and ${ }^{4}$ Pathology, Hiroshima University Institute of Biomedical and Health Sciences; \\ ${ }^{5}$ Department of Anatomical Pathology, Hiroshima University Hospital, Hiroshima 734-8551, Japan
}

Received January 31, 2016; Accepted December 20, 2016

DOI: 10.3892/ol.2017.6119

\begin{abstract}
An atomic bomb (A-bomb) was dropped on Hiroshima on 6th August 1945. Although numerous studies have investigated cancer incidence and mortality among A-bomb survivors, only a small number have addressed urological cancer in these survivors. The aim of the present study was to investigate the clinicopathological features of prostate cancer (PCa) in A-bomb survivors. The clinicopathological features and prognosis of $\mathrm{PCa}$ were retrospectively reviewed in 212 survivors and 595 control patients between November 1996 and December 2010. The histopathological and clinical outcomes of surgical treatment of PCa were also evaluated in 69 survivors and 162 control patients. Despite the higher age at diagnosis compared with the control group $(\mathrm{P}=0.0031)$, survivors were more likely to have been diagnosed with $\mathrm{PCa}$ from a health check compared with the control group $(\mathrm{P}<0.0001)$. As a consequence, the survivors were found to exhibit metastasis significantly less frequently (199/212, 93.9\%) compared with the control patients (521/595, 87.6\%; $\mathrm{P}=0.0076)$. Prognosis in the two groups was examined, subsequent to a mean length of follow-up of 44 months. Overall survival (OS) and PCa-specific survival (CS) were similar between the two groups (OS, $\mathrm{P}=0.2196$; $\mathrm{CS}$, $\mathrm{P}=0.1017)$. A-bomb exposure was not found to be an independent predictor for prognosis by multivariate analysis (OS, $\mathrm{P}=0.7800 ; \mathrm{CS}, \mathrm{P}=0.8688)$. The clinicopathological features of patients who underwent a prostatectomy were similar except for the diagnosis opportunity between the two groups.
\end{abstract}

Correspondence to: Dr Jun Teishima, Department of Urology, Hiroshima University Institute of Biomedical and Health Sciences, 1-2-3 Kasumi, Hiroshima 734-8551, Japan

E-mail: teishima@hiroshima-u.ac.jp

Key words: atomic bomb, prostate cancer, clinicopathological features
Progression-free survival rates were similar between the two groups $(\mathrm{P}=0.5630)$. A-bomb exposure was not a significant and independent predictor for worsening of progression-free prognosis by multivariate analysis $(\mathrm{P}=0.3763)$. A-bomb exposure does not appear to exert deleterious effects on the biological aggressiveness of PCa and the prognosis of patients with PCa.

\section{Introduction}

An atomic bomb (A-bomb) was dropped on Hiroshima, Japan, on 6th August 1945. The A-bomb explosion produced enormous destruction, the mortality of numerous people in an instant and the emission of a high amount of radiation that exhibited deleterious effects on the human population (1). Since then, A-bomb survivors have suffered from radiation-associated health effects $(2,3)$. The Atomic Bomb Casualty Commission (ABCC) carried out systematic studies on the effects of the A-bomb on the human body, and the Radiation Effects Research Foundation (RERF) has continued this work. Until the present day, scientists of this foundation have periodically reported radiation-associated health effects, including cancer and other diseases, in the A-bomb survivors $(3,4)$. At present, $>70$ years have passed since exposure to the A-bomb. The most important type of evidence regarding the late effects of A-bomb radiation exposure on mortality is that of an increased risk of cancer mortality throughout life (4). A-bomb-associated radiation risk estimates differ by organ sites. The pattern of radiation-related risks for solid cancer exhibits a gradual increase starting several years after the bombings, while the risk of leukemia increased in the early period immediately subsequent to the bombing, and then decreased $(4,5)$. Although the clinicopathological features of several types of cancer have been investigated in these survivors (6-8), there are only a small number of studies on the clinicopathological features of urological cancer. To the best of our knowledge, there has been no report about the features of prostate cancer (PCa) in A-bomb survivors. In the present study, the differences in clinicopathological features 
Table I. Clinicopathological features in patients with prostate cancer.

\begin{tabular}{|c|c|c|c|}
\hline Feature & $\begin{array}{l}\text { Control patients } \\
\quad(\mathrm{n}=595)\end{array}$ & $\begin{array}{l}\text { A-bomb survivors } \\
\quad(\mathrm{n}=212)\end{array}$ & P-value \\
\hline Mean age at diagnosis, years (range) & $71(57-92)$ & $73(59-93)$ & 0.0031 \\
\hline \multicolumn{4}{|l|}{ Diagnosis opportunity $(\%)$} \\
\hline Health check & $138(23.2)$ & $96(45.3)$ & \multirow[t]{2}{*}{$<0.000$} \\
\hline Consultation & $457(76.8)$ & $116(54.7)$ & \\
\hline Initial PSA value (ng/ml) & 10.28 & $9.3(3.14-1969.55)$ & 0.0529 \\
\hline \multicolumn{4}{|l|}{ Gleason score $(\%)$} \\
\hline$\leq 6$ & $164(27.6)$ & $52(24.5)$ & \multirow[t]{3}{*}{0.3211} \\
\hline 7 & $237(39.8)$ & $97(45.8)$ & \\
\hline$\geq 8$ & $194(32.6)$ & $63(29.7)$ & \\
\hline \multicolumn{4}{|l|}{$\begin{array}{l}\text { Clinical stage grouping } \\
\text { (Jewett Staging System) (\%) }\end{array}$} \\
\hline $\mathrm{A} / \mathrm{B}$ & $464(78)$ & $186(87.7)$ & \multirow[t]{3}{*}{0.0076} \\
\hline $\mathrm{C}$ & $57(9.6)$ & $13(6.1)$ & \\
\hline $\mathrm{D}$ & $74(12.4)$ & $13(6.1)$ & \\
\hline \multicolumn{4}{|l|}{ Method of initial treatment (\%) } \\
\hline Prostatectomy & $188(31.6)$ & $79(37.3)$ & \multirow[t]{4}{*}{0.0807} \\
\hline Brachytherapy & $131(22.0)$ & $30(14.2)$ & \\
\hline External radiation therapy & 87 (14.6) & $35(16.5)$ & \\
\hline Hormone therapy & $189(31.8)$ & $68(32.1)$ & \\
\hline
\end{tabular}

A-bomb, atomic bomb; PSA, prostate-specific antigen; Clinical state group A/B, cancer that is confined to the prostate tissues; Clinical state group $\mathrm{C}$, cancer that has developed outside of the prostate tissues, but has not metastasized to the lymph nodes or other distal organs; Clinical state group D, prostate cancer that has metastasized to the lymph nodes or other distal organs, Gleason score, prostate biopsy sample grading system.

and prognosis of PCa between A-bomb survivors and those not exposed were investigated.

\section{Patients and methods}

Patients. A total of 1,020 patients were diagnosed with $\mathrm{PCa}$ and treated in Hiroshima University Hospital, Hiroshima, Japan, between November 1996 and December 2010. Of these patients, 213 born subsequent to July 1946 were excluded. Therefore, 807 patients including 212 A-bomb survivors and 595 unexposed patients of the same generation classified as the control group were enrolled in the present study. The present study has been approved by the ethical committee of the Hiroshima University Hospital (Research approval no. E-200) and all patients were given the option to opt-out. Several clinicopathological factors, consisting of median age at the time of diagnosis, initial prostate-specific antigen (PSA) value, diagnosis opportunity (whether or not diagnosis was made at a routine health checkup), biopsy Gleason score, clinical stage grouping (Jewett Staging System of PCa) (9), choice of treatment and prognosis were compared between the A-bomb survivors and control patients.

Follow-up. Subsequent to the initiation of PCa treatment, all patients were followed up with physical examinations and blood analysis including PSA value every 4-12 weeks, with computed tomography and bone scans added if necessary.
The median length of follow-up for patients in this study was 44 months, ranging between 1 and 159 months.

Statistical analysis. All data are presented as the prevalence or median. Statistical analysis was performed using a Mann-Whitney U test, and a $\chi^{2}$ test was used for categorical data. Survival was analyzed using the Kaplan-Meier method. Log-rank statistics were used to compare survival rate. $\mathrm{P}<0.05$ was considered to indicate a statistically significant difference. Prognostic factors associated with a worsening of survival were determined using the Cox proportional hazard model.

\section{Results}

Clinicopathological features of patients with PCa. The clinicopathological features of the A-bomb survivors and control patients are illustrated in in Table I. The diagnosis age, diagnosis opportunity and clinical stage groupings were significantly different in survivors compared with control patients $(\mathrm{P}=0.0031$, $\mathrm{P}<0.0001$ and $\mathrm{P}=0.0076$ ), whereas initial PSA value, biopsy Gleason score, and choice of treatment were similar between the survivors and control patients. The rate of patients with clinical stage D was $6.1 \%$ in survivors, and was significantly lower than $12.4 \%$ in the control patients group $(\mathrm{P}=0.0076)$.

Survival rates and multivariate analyses of $P C a$ patients. Overall survival (OS) and PCa-specific survival (CS) curves 
Table II. Multivariate analysis of prognostic factors for overall survival in prostate cancer patients.

\begin{tabular}{|c|c|c|c|c|}
\hline \multirow[b]{2}{*}{ Variable } & \multirow{2}{*}{$\begin{array}{c}\begin{array}{c}\text { Univariate analysis } \\
\text { (log-rank test })\end{array} \\
\text { P-value }\end{array}$} & \multicolumn{3}{|c|}{$\begin{array}{c}\text { Multivariate analysis } \\
\text { (Cox's regression analysis) }\end{array}$} \\
\hline & & Risk ratio & $95 \% \mathrm{CI}$ & P-value \\
\hline Bombed & 0.2196 & & & \\
\hline Control patients & & 1 & & \\
\hline Atomic bomb survivors & & 0.932 & $0.558-1.504$ & 0.78 \\
\hline Age at diagnosis (years) & $<0.0001$ & & & \\
\hline$\leq 70$ & & 1 & & \\
\hline$\geq 71$ & & 2.028 & $1.155-3.322$ & 0.0127 \\
\hline Diagnosis opportunity & $<0.0001$ & & & \\
\hline Health check & & 1 & & \\
\hline Consultation & & 1.546 & $0.793-3.322$ & 0.2105 \\
\hline Initial PSA value (ng/ml) & $<0.0001$ & & & \\
\hline$\leq 10$ & & 1 & & \\
\hline$>10$ & & 1.36 & $0.771-2.461$ & 0.2919 \\
\hline Gleason score & $<0.0001$ & & & \\
\hline$\leq 6$ & & 1 & & \\
\hline 7 & & 1.593 & $0.827-3.275$ & 0.1687 \\
\hline$\geq 8$ & & 1.741 & $0.855-3.759$ & 0.129 \\
\hline Clinical stage grouping & $<0.0001$ & & & \\
\hline $\mathrm{A} / \mathrm{B}$ & & 1 & & \\
\hline $\mathrm{C}$ & & 1.509 & $0.773-2.856$ & 0.222 \\
\hline $\mathrm{D}$ & & 1.868 & $1.024-3.440$ & 0.0417 \\
\hline Method of initial treatment & $<0.0001$ & & & \\
\hline Prostatectomy & & 1 & & \\
\hline Brachytherapy & & 0.883 & $0.230-2.906$ & 0.8427 \\
\hline External radiation therapy & & 0.967 & $0.255-3.134$ & 0.9573 \\
\hline Hormone therapy & & 5.301 & $2.479-12.749$ & $<0.0001$ \\
\hline
\end{tabular}

$\mathrm{CI}$, confidence interval; PSA, prostate-specific antigen; Clinical state group $\mathrm{A} / \mathrm{B}$, cancer that is confined to the prostate tissues; Clinical state group $\mathrm{C}$, cancer that has developed outside of the prostate tissues, but has not metastasized to the lymph nodes or other distal organs; Clinical state group D, prostate cancer that has metastasized to the lymph nodes or other distal organs, Gleason score, prostate biopsy sample grading system.

following the initiation of $\mathrm{PCa}$ treatment in all patients are demonstrated in Figs. 1 and 2, respectively. There was no significant difference between survivors and control patients in either 5-year OS (91.0 and 86.3\%, respectively, $\mathrm{P}=0.2196$ ) or CS (95.7 and 94.6\%, respectively, $\mathrm{P}=0.1017$ ).

The multivariate analysis revealed that age at diagnosis, clinical stage grouping, and method of treatment but not A-bomb exposure were independent predictors for a poorer overall prognosis, as summarized in Table II, and that clinical stage grouping but not A-bomb exposure was also an independent predictor for a poorer $\mathrm{PCa}$-specific prognosis, as summarized in Table III.

Clinicopathological features of PCa patients who underwent prostatectomy. The histopathological outcomes of the surgical treatment of PCa were evaluated in 69 survivors and 162 control patients. Several clinicopathological factors of the 231 patients who underwent a prostatectomy, consisting of mean age at the time of diagnosis, initial PSA value, diagnosis opportunity, biopsy Gleason score, pathological Gleason score, pathological primary tumor $(\mathrm{T})$ stage grouping (Union for International Cancer Control tumor node metastasis Classification of PCa) (10) and surgical margin status were compared between the two groups. Of the clinicopathological features of patients who underwent a prostatectomy, age at diagnosis, initial PSA value, biopsy Gleason score, pathological T stage, pathological Gleason score and surgical margin status were similar between the two groups, whereas the proportion of patients diagnosed by medical examination was significantly higher in the survivors compared with the control patients $(\mathrm{P}=0.0007)$, as summarized in Table IV.

Progression-free survival (PFS) rate and multivariate analysis of PCa patients who underwent prostatectomy. The PFS curves following surgical treatment in the 231 patients are demonstrated in Fig. 3. The 5-year PFS rates in the 
Table III. Multivariate analysis of prognostic factors for prostate cancer-specific survival.

\begin{tabular}{|c|c|c|c|c|}
\hline \multirow[b]{2}{*}{ Variable } & \multirow{2}{*}{$\begin{array}{c}\begin{array}{c}\text { Univariate analysis } \\
\text { (log-rank test })\end{array} \\
\text { P-value }\end{array}$} & \multicolumn{3}{|c|}{$\begin{array}{c}\text { Multivariate analysis } \\
\text { (Cox's regression analysis) }\end{array}$} \\
\hline & & Risk ratio & $95 \% \mathrm{CI}$ & P-value \\
\hline Bombed & 0.1062 & & & \\
\hline Control patients & & 1 & & \\
\hline Atomic bomb survivors & & 0.932 & $0.369-2.054$ & 0.8688 \\
\hline Age at diagnosis (years) & 0.0226 & & & \\
\hline$\leq 70$ & & 1 & & \\
\hline$\geq 71$ & & 1.83 & $0.852-4.393$ & 0.1254 \\
\hline Diagnosis opportunity & 0.0063 & & & \\
\hline Health check & & 1 & & \\
\hline Consultation & & 1.272 & $0.444-4.635$ & 0.675 \\
\hline Initial PSA value (ng/ml) & $<0.0001$ & & & \\
\hline$\leq 10$ & & 1 & & \\
\hline$>10$ & & 1.751 & $0.574-6.212$ & 0.338 \\
\hline Gleason score & $<0.0001$ & & & \\
\hline$\leq 6$ & & 1 & & \\
\hline 7 & & 2.892 & $0.722-19.354$ & 0.143 \\
\hline$\geq 8$ & & 2.942 & $0.715-20.310$ & 0.1458 \\
\hline Clinical stage grouping & $<0.0001$ & & & \\
\hline $\mathrm{A} / \mathrm{B}$ & & 1 & & \\
\hline $\mathrm{C}$ & & 2.71 & $0.491-13.292$ & 0.2362 \\
\hline $\mathrm{D}$ & & 17.739 & $4.943-85.313$ & $<0.0001$ \\
\hline Method of initial treatment & $<0.0001$ & & & \\
\hline Prostatectomy & & 1 & & \\
\hline Brachytherapy & & 0.419 & $0.019-3.756$ & 0.4544 \\
\hline External radiation therapy & & 2.222 & $0.393-12.658$ & 0.3495 \\
\hline Hormone therapy & & 1.101 & $0.211-6.264$ & 0.9083 \\
\hline
\end{tabular}

survivors and control patients were 62.4 and $65.0 \%$, respectively $(\mathrm{P}=0.5630)$. The multivariate analysis revealed that initial PSA value, pathological $\mathrm{T}$ stage grouping and surgical margin status, but not A-bomb exposure, were independent predictors for a poorer PFS, as summarized in Table V.

\section{Discussion}

The data from the present study demonstrated that exposure to a radiation dose from the A-bomb did not result in a poorer prognosis for patients with $\mathrm{PCa}$. This is the first study to investigate the differences in clinicopathological features and prognosis of $\mathrm{PCa}$ between A-bomb survivors and those not exposed. Scientists in the ABCC and RERF have been assessing the long-term health effects in the survivors of the atomic bombings $(11,12)$ in a study program being conducted termed the Life Span Study (LSS). In a series of studies, the radiation risk estimates of cancer incidence and mortality have been periodically published, which reported that radiation risk estimates differ by organ site (4). Although the reason for the differences in radiation risk of organ sites is not clear, significant increases in cancer incidence are observed for the majority of sites, such as the stomach, oral cavity, esophagus, colon, liver, lung and bladder. Also, a significantly increased risk of cancer mortality has been observed for the majority of sites, such as the stomach, lung, liver, colon and bladder $(3,13)$.

Yamamoto et al (6) compares the clinical features of gastric cancers between A-bomb survivors and control patients, whereby the results of surgical treatment for gastric cancer were reviewed and the clinicopathological characteristics of these two groups were compared. In their study, cancer formation in the stomach was assumed to follow alternative pathways in the A-bomb survivors and the control patients as the characteristic features and survival rates between the two groups differed significantly. The results of the aforementioned study on gastric cancer correspond to 
Table IV. Clinicopathological features in prostate cancer patients who underwent a prostatectomy.

\begin{tabular}{|c|c|c|c|}
\hline Feature & $\begin{array}{l}\text { Control patients } \\
\qquad(n=162)\end{array}$ & $\begin{array}{l}\text { Atomic bomb survivors } \\
\qquad(n=69)\end{array}$ & P-value \\
\hline Age at diagnosis (years) & $68(57-77)$ & $70(59-79)$ & 0.1297 \\
\hline \multicolumn{4}{|l|}{ Diagnosis opportunity } \\
\hline Health check $(\%)$ & $55(34.0)$ & $40(58.0)$ & \multirow[t]{2}{*}{0.0007} \\
\hline Consultation (\%) & $107(66.0)$ & $29(42.0)$ & \\
\hline Initial PSA value (ng/ml) & $8.15(1.53-82.83)$ & $9.45(3.14-53.21)$ & 0.3907 \\
\hline \multicolumn{4}{|l|}{ Biopsy Gleason score (\%) } \\
\hline$\leq 6$ & $54(33.3)$ & $16(23.2)$ & \multirow[t]{3}{*}{0.2916} \\
\hline 7 & $68(42.0)$ & $32(46.4)$ & \\
\hline$\geq 8$ & $40(24.7)$ & $21(30.4)$ & \\
\hline \multicolumn{4}{|l|}{$\begin{array}{l}\text { Pathologic } \mathrm{T} \text { stage grouping } \\
\text { (TNM Classification) }(\%)\end{array}$} \\
\hline pT2 & $105(64.8)$ & $45(65.2)$ & \multirow[t]{2}{*}{0.9267} \\
\hline$\geq \mathrm{pT} 3$ & $57(35.2)$ & $24(34.8)$ & \\
\hline \multicolumn{4}{|c|}{ Pathological Gleason score (\%) } \\
\hline$\leq 6$ & $16(9.9)$ & $15(21.7)$ & \multirow[t]{3}{*}{0.0525} \\
\hline 7 & $102(63.0)$ & $37(53.6)$ & \\
\hline$\geq 8$ & $44(27.2)$ & $17(24.6)$ & \\
\hline \multicolumn{4}{|l|}{ Surgical margin $(\%)$} \\
\hline Negative & $85(52.5)$ & $38(55.1)$ & \multirow[t]{2}{*}{0.7166} \\
\hline Positive & $77(47.5)$ & $31(44.9)$ & \\
\hline
\end{tabular}

PSA, prostate-specific antigen; Clinical state group A/B, cancer that is confined to the prostate tissues; Clinical state group C, cancer that has developed outside of the prostate tissues, but has not metastasized to the lymph nodes or other distal organs; Clinical state group D, prostate cancer that has metastasized to the lymph nodes or other distal organs, Gleason score, prostate biopsy sample grading system.

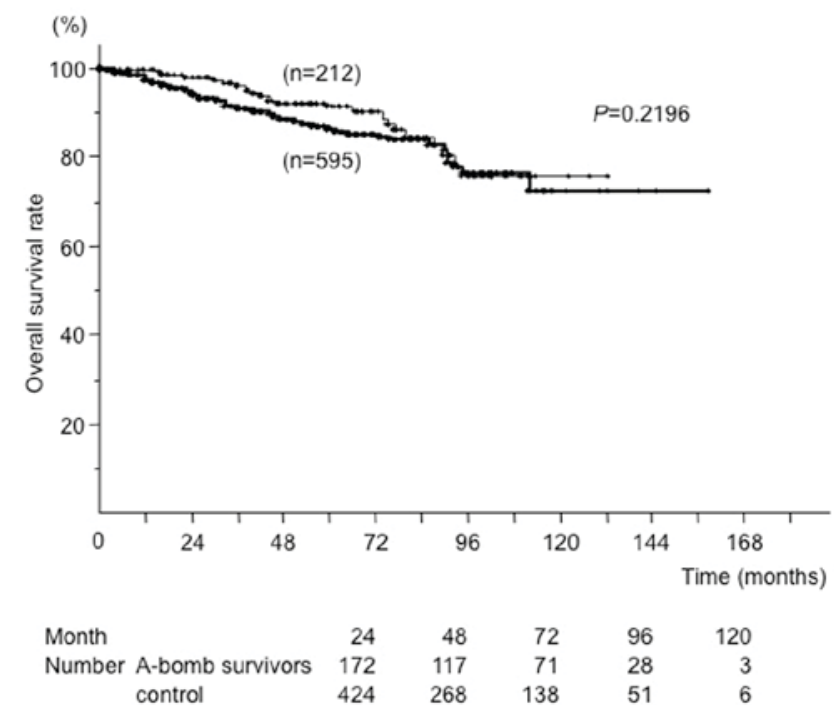

Figure 1. Overall survival rates of all patients. There was no significant difference in survival rates between A-bomb survivors and control patients. Thick line, control patients; thin line, A-bomb survivors. A-bomb, atomic bomb.

the results of the LSS study. In contrast, significant increases were not exhibited in prostate cancer incidence or risk of cancer mortality in the RERF report. In addition, there is no report on the clinicopathological features of $\mathrm{PCa}$ in $\mathrm{A}$-bomb

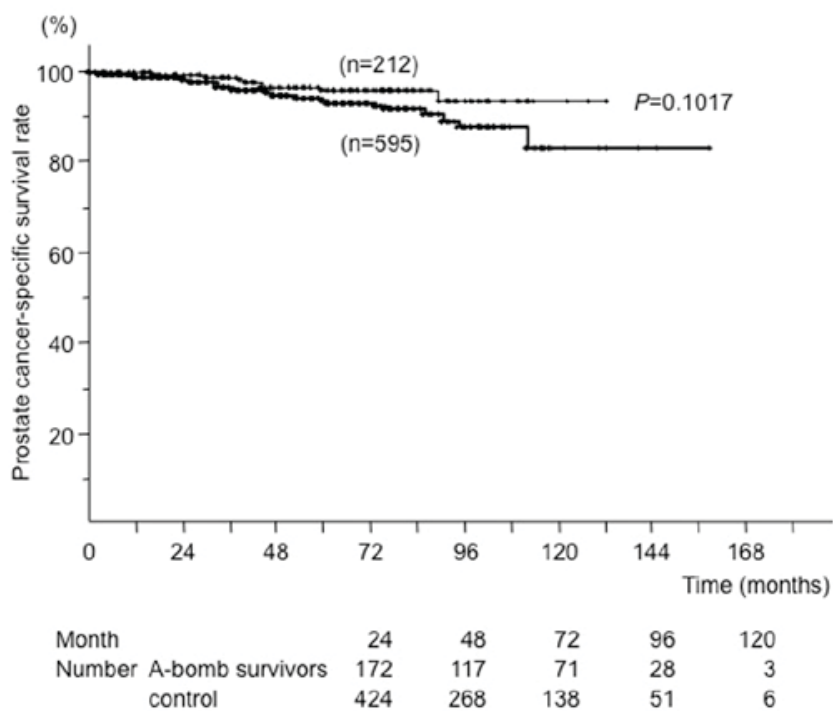

Figure 2. Prostate cancer-specific survival rates. There was no significant difference in survival between A-bomb survivors and control patients. Thick line, control patients; thin line, A-bomb survivors. A-bomb, atomic bomb.

survivors. Therefore, the present study focused on PCa of this group. Despite their high age, A-bomb survivors have been diagnosed significantly more frequently with $\mathrm{PCa}$ through health checks compared with the control group patients, and 
Table V. Multivariate analysis of prognostic factors for progression-free survival in prostate cancer patients who underwent a prostatectomy.

\begin{tabular}{|c|c|c|c|c|}
\hline \multirow[b]{2}{*}{ Variable } & \multirow{2}{*}{$\begin{array}{l}\begin{array}{c}\text { Univariate analysis } \\
\text { (log-rank test) }\end{array} \\
\text { P-value }\end{array}$} & \multicolumn{3}{|c|}{$\begin{array}{c}\text { Multivariate analysis } \\
\text { (Cox's regression analysis) }\end{array}$} \\
\hline & & Risk ratio & $95 \% \mathrm{CI}$ & P-value \\
\hline Bombed & 0.5602 & & & \\
\hline Control patients & & 1 & & \\
\hline Atomic bomb survivors & & 1.258 & $0.751-2.065$ & 0.3763 \\
\hline Initial PSA value (ng/ml) & $<0.0001$ & & & \\
\hline$\leq 10$ & & 1 & & \\
\hline$>10$ & & 2.007 & $1.206-3.390$ & 0.0072 \\
\hline Pathological T stage grouping & $<0.0001$ & & & \\
\hline pT2 & & 1 & & \\
\hline$\geq \mathrm{pT} 3$ & & 2.425 & $1.417-4.229$ & 0.0012 \\
\hline Pathological Gleason score & 0.0004 & & & \\
\hline$\leq 6$ & & 1 & & \\
\hline 7 & & 1.092 & $0.479-2.947$ & 0.8452 \\
\hline$\geq 8$ & & 2.124 & $0.853-6.065$ & 0.1085 \\
\hline Surgical margin & $<0.0001$ & & & \\
\hline Negative & & 1 & & \\
\hline Positive & & 3.518 & $1.893-6.949$ & $<0.0001$ \\
\hline
\end{tabular}

Patients were classified according to the Union for International Cancer Control's TNM Classification of Malignant Tumors (7th edition). PSA, prostate-specific antigen; Gleason score, prostate biopsy sample grading system.

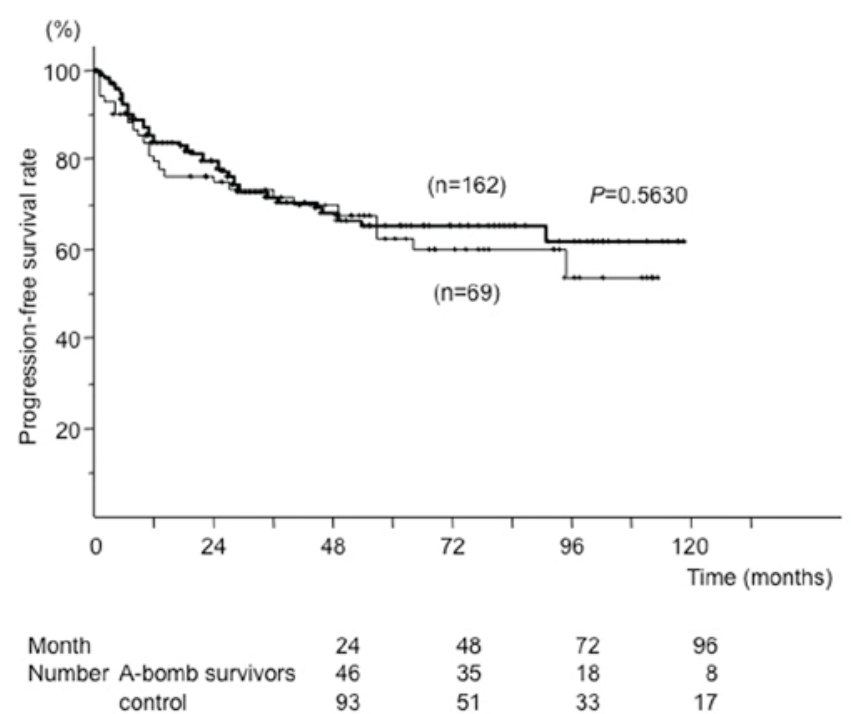

Figure 3. Progression-free survival rates of prostate cancer patients who underwent a prostatectomy. There was no significant difference in survival between A-bomb survivors and control patients. Thick line, control patients; thin line, A-bomb survivors. A-bomb, atomic bomb.

they were diagnosed at a low clinical stage, as summarized in Table I. The debate concerning the reason for these results is associated with the fact that A-bomb survivors have expressed concerns about increasing cancer risk and mortality following A-bomb exposure, and as the Atomic Bomb Victims' Relief
Law has been applied to them, it is possible for them to receive medical examinations and treatment at the expense of the national government $(4,14)$. As demonstrated in Fig. 1, no significant difference was found in the OS rates between survivors and control patients. In the present study, diagnosis age, clinical stage grouping and method of initial treatment were significant prognostic factors for OS in the multivariate analysis. However, A-bomb exposure was not a significant prognostic factor for OS, as illustrated in Table II. The higher age but lower clinical stage of the survivors is cited as one of the reasons for no difference in OS rate between the two groups being observed. Also, no significant difference was observed in CS rates between the two groups, as demonstrated in Fig. 2. Clinical stage grouping, but not A-bomb exposure, was a significant prognostic factor for CS in the multivariate analysis, as summarized in Table III. The extension of the observation period may reveal a difference in CS rates as the natural history of $\mathrm{PCa}$ is relatively long, and survivors exhibit $\mathrm{PCa}$ of a lower stage compared with the control patients.

In addition, the subgroup of patients who underwent surgery without neoadjuvant or combination therapy were examined. In the patients who underwent prostatectomy, a significant difference was observed in the diagnosis opportunity between A-bomb survivors and control patients. The multivariate analysis demonstrated that A-bomb exposure was not a significant prognostic factor for PFS, as illustrated in Table V. The carcinogenic effects of ionizing radiation have been investigated with respect to certain organs (15). Whilst it is accepted that ionizing radiation damages cellular DNA and 
causes mutations (16), the association between $\mathrm{PCa}$ and radiation has not been investigated. The mechanism underlying the difference in radiation risk of various organ sites requires attention.

In summary, no difference in clinicopathological features of PCa was observed between the two groups in the present study. The results obtained also support the RERF data that the prostate appears to be less susceptible to exposure from A-bomb radiation. Although the present study did not reveal an increase in the incidence of PCa due to A-bomb exposure, it did demonstrate that A-bomb exposure did not exert adverse effects on PCa cancer mortality of the survivors. If there is an effect on the incidence of PCa by A-bomb exposure, the present study suggests that $\mathrm{PCa}$ in survivors may be treated to the same extent as in patients not exposed to the A-bomb, through early detection by the social health system, and caution.

\section{References}

1. Douple EB, Mabuchi K, Cullings HM, Preston DL, Kodama K Shimizu Y, Fujisawa S and Shore RE: Long-term radiation-related health effects in a unique human population: Lessons learned from the atomic bomb survivors of Hiroshima and Nagasaki. Disaster Med Public Health Prep 5 (Suppl 1): S122-S133, 2011.

2. Moloney WC and Kastenbaum MA: Leukemogenic effects of ionizing radiation on atomic bomb survivors in Hiroshima City. Science 121: 308-309, 1955.

3. Ozasa K, Shimizu Y, Suyama A, Kasagi F, Soda M, Grant EJ, Sugiyama R, Sakata R, Sugiyama H and Kodama K: Studies of the mortality of atomic bomb survivors, Report 14, 1950-2003: An overview of cancer and noncancer diseases. Radiat Res 177: 229-243, 2012.

4. Beebe GW, Ishida M and Jablon S: Studies of the mortality of A-bomb survivors. I. Plan of study and mortality in the medical subsample (selection 1), 1950-1958. Radiat Res 16: 253-280, 1962.
5. Sakata R, Grant EJ and Ozasa K: Long-term follow-up of atomic bomb survivors. Maturitas 72: 99-103, 2012.

6. Yamamoto M, Matsuyama A, Kameyama T, Okamoto M, Okazaki J, Utsunomiya T, Tsutsui S and Ishida T: The long-term outcome of atomic bomb survivors with gastric carcinoma. J Surg Oncol 100: 594-597, 2009.

7. Fukuhara T, Sharp GB, Mizuno T, Itakura H, Yamamoto M, Tokunaga M, Tokuoka S, Cologne JB, Fujita Y, Soda M and Mabuchi K: Liver cancer in atomic-bomb survivors: Histological characteristics and relationships to radiation and hepatitis $\mathrm{B}$ and C viruses. J Radiat Res 42: 117-130, 2001.

8. Egawa H, Furukawa K, Preston D, Funamoto S, Yonehara S, Matsuo T, Tokuoka S, Suyama A, Ozasa K, Kodama K and Mabuchi K: Radiation and smoking effects on lung cancer incidence by histological types among atomic bomb survivors. Radiat Res 178: 191-201, 2012.

9. Jewett HJ: The present status of radical prostatectomy for stages A and B prostatic cancer. Urol Clin North Am 2: 105-124, 1975.

10. Sobin LH, Gospodarowicz MK and Wittekind C: TNM classification of Malignant Tumours. 7th edition. Wiley-Blackwell, Hoboken, NJ, 2009.

11. Ozasa K, Shimizu Y, Sakata R, Sugiyama H, Grant EJ, Soda M, Kasagi F and Suyama A: Risk of cancer and non-cancer diseases in the atomic bomb survivors. Radiat Prot Dosimetry 146: 272-275, 2011.

12. Preston DL, Cullings H, Suyama A, Funamoto S, Nishi N, Soda M, Mabuchi K, Kodama K, Kasagi F and Shore RE: Solid cancer incidence in atomic bomb survivors exposed in utero or as young children. J Natl Cancer Inst 100: 428-436, 2008.

13. Preston DL, Ron E, Tokuoka S, Funamoto S, Nishi N, Soda M, Mabuchi K and Kodama K: Solid cancer incidence in atomic bomb survivors: 1958-1998. Radiat Res 168: 1-64, 2007.

14. Mimura M: The Relief of Hibakusha and our Role. Life Of People. Community And Social Welfare, Japan, 1981.

15. Nowell PC, Cole LJ and Ellis ME: Neoplasms of the glandular stomach in mice irradiated with x-rays or fast neutrons. Cancer Res 18: 257-260, 1958

16. Maruta K and Shida H: Some factors which influence prognosis after surgery for advanced gastric cancer. Ann Surg 167: 313-318, 1968. 